
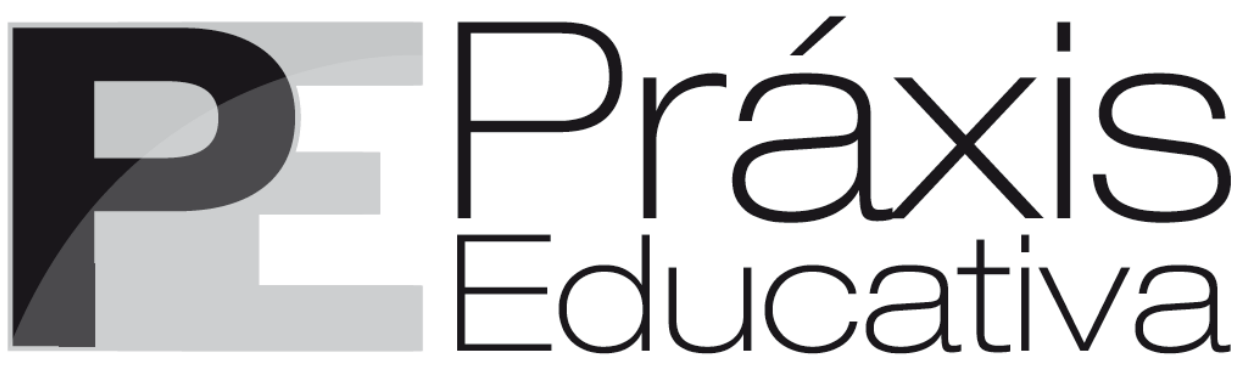

ISSN 1809-4309 (Versão online) DOI: 10.5212/PraxEduc.v.12i1.0016

\title{
PIAGET, Jean. Relações entre a afetividade e a inteligência no desenvolvimento mental da criança. Tradução e organização: Cláudio J. P. Saltini e Doralice B. Cavenaghi. Rio de Janeiro: Wak, 2014. 356 p.
}

Kellys Regina Rodio Saucedo*

Os últimos séculos parecem vislumbrar no campo educacional uma visão dicotômica entre o racional e o emocional. $\mathrm{Na}$ escola, em geral, o que se é priorizado em maior grau de importância é o aspecto cognitivo em relação à dimensão afetiva da criança. Por outro lado, estudos mais recentes têm considerado a indissociabilidade entre o racional e o emocional (DAMÁSIO, 1996; LEITE; TASSONI, 2001; ULLER; ROSSO, 2009), confirmando implicações já apontadas por Jean Piaget, na década de 1950, sobre a importância da afetividade para o desenvolvimento da inteligência.

A seguir, pretende-se discorrer sobre um curso ministrado por Piaget, na Sorbonne, em 1953-1954, e traduzido por Claudio Santini e Doralice Cavenaghi. Nesse curso, o autor explora em profundidade, a partir de um conjunto significativo de argumentos - divididos em três grandes partes, pelos tradutores da obra - as relações entre a afetividade e a inteligência no desenvolvimento mental da criança. Em síntese, a tese defendida nesse curso, ministrado por Piaget, foi a de que: "A afetividade desempenharia, então, uma fonte energética, da qual dependeria o funcionamento da inteligência, mas não suas estruturas [...]” (PIAGET, 2014, p. 43). Uma temática bastante intrigante para aqueles autores que, sem uma posição problematizadora, alegam que a afetividade não foi objeto dos estudos piagetianos. Não se trata de uma leitura para iniciantes, apesar de haver coerência entre as partes e do autor recuperar, em diferentes momentos, suas hipóteses e seus problemas iniciais para analisá-los à luz dos elementos teóricos evocados. Isso porque a proficiência conceitual de Piaget e a trajetória de uma vida dedicada à pesquisa representam um verdadeiro desafio para leigos na temática. Assim, a obra é certamente desafiante, mas oportuna no contexto atual - em que as características do sujeito psicológico têm suscitado cada vez mais questionamentos (também) às Ciências Humanas.

A primeira parte, intitulada Periodo dos sentimentos intraindividuais, sugere uma excursão por conceituações basilares para o entendimento do campo da afetividade e das estruturas cognitivas (envolvendo as operações lógicas e matemáticas, a percepção, as teorias clássicas da conduta e a análise da noção de estrutura); dos estágios do desenvolvimento intelectual e afetivo (percorrendo as fases deste desenvolvimento, pontuando suas principais características, a saber: (i) primeiro estágio, das formações hereditárias; (ii) segundo estágio, dos afetos perceptivos e das formas

\footnotetext{
*Doutoranda em Educação pela Universidade de São Paulo (USP). E-mail: <kellys@usp.br>.
} 
PIAGET, Jean. Relações entre a afetividade e a inteligência no desenvolvimento mental da criança...

diferenciadas do contentamento e da decepção; (iii) terceiro estágio, dos afetos intencionais). É interessante apontar que, em cada explanação teórica, o autor fecha a seção apresentando suas conclusões sobre o estágio implicado.

A partir do terceiro estágio, Os afetos intencionais, Piaget apresenta: a noção de valorização, por Pierre Janet; a teoria da necessidade, de Edouard Claparède; a teoria das formas, por Kurt Lewin; e o narcisismo e a escolha do objeto, segundo a psicanálise freudiana. As concepções de interesse e valor, de Claparède, norteiam a qualidade "energética" da conduta que embasa as formulações piagetianas. Apesar de o esquema ter sido considerado pelo autor demasiado simplista, Piaget procurou agregar a regulação energética, que já tinha feito parte das valorações de Janet, ao sistema de interesses, de Claparède. Segundo Piaget, os valores são o ponto inicial dos sentimentos, o que o levou a incluir também à sua tese as concepções de noção de campo total com fatores intelectuais e afetivos de Lewin. Tais elementos teóricos sustentam o tópico, no qual Piaget aborda a Construção simultânea do objeto afetivo e cognitivo. À guisa de reflexão, afirmar-se que existem diferentes modelos interpretativos da relação entre a afetividade e a inteligência. Freud, por exemplo, valoriza as moções pulsionais e o modo como estas intervêm no funcionamento cognitivo e afetivo; Vygotsky enfatiza a complementaridade entre afetividade e inteligência, enquanto Piaget defende a correspondência entre um e outro com argumentos e contra-argumentos.

A segunda parte, Periodo dos Sentimentos Interindividuais, fundamenta as estruturas organizadoras dos estágios piagetianos IV, V e VI. Destaca-se, nessa subdivisão, a gênese da função simbólica da linguagem; os sentimentos individuais (egocentrismo, sentimentos de inferioridade e superioridade); o aparecimento dos sentimentos morais - ponto em que foram emitidas críticas à interpretação freudiana, de esquema topográfico do inconsciente; a tese de Bovet, nos aspectos que regulam o sentimento de dever -, e os sentimentos seminormativos, que emergem da situação pré-operatória da inteligência. Na sequência, são explicitadas as operações concretas, de reversibilidade e de conservação, características do quinto estágio. Além de problematizar a função dos sentimentos intermediários como objeto de orientação para conservação, nesse tópico, o autor diferencia a lógica da inteligência da lógica dos sentimentos para então introduzir reflexões sobre as operações afetivas, analisadas em termos da vontade e do respeito. O sexto estágio encerra a parte II e caracteriza-se pela origem das operações formais. Nesse ponto, a novidade está na ação combinatória dos mecanismos de inserção intelectual e afetiva, que regem a inclusão do adolescente nas relações em sociedade. O movimento do pensamento psicológico é enfocado nas vozes de Charles Blondel, Théodule Ribot e Emile Meyerson para analisar as transformações na vida afetiva dos sujeitos, em questões problematizadoras que envolvem a formação da personalidade e a realização da pessoa.

$\mathrm{Na}$ terceira parte, que conclui a obra, a função do jogo é inserida em meio a considerações aglutinadoras dos tópicos que alicerçaram as duas primeiras partes da obra. Piaget recupera suas hipóteses iniciais sobre as relações entre as funções afetivas e intelectuais do sujeito. Em síntese compreensiva, o autor recupera os sentimentos morais, a vontade, os interesses e os valores, concluindo que não existe uma intelectualização dos sentimentos, mas "[...] uma intelectualização dos elementos da conduta em relação às pessoas, uma intelectualização dos elementos pessoais, em oposição aos elementos que se relacionam como objeto em geral" (PIAGET, 2014, p. 289). Nesse caso, segundo o autor, não se pode pensar em estruturas afetivas, mas em estruturas das condutas relativas às pessoas. Diante disso, um problema permanece, que, conforme Piaget, regulará todo o final do curso que é o do jogo simbólico e do pensamento simbólico na criança. Alguns questionamentos ordenam as próximas seções no sentido de compreender as manifestações da afetividade e a elaboração das estruturas cognitivas. Para isso,

Práxis Educativa, Ponta Grossa, v. 12, n. 1, p. 287-289, jan./abr. 2017 Disponível em: <http://www.revistas2.uepg.br/index.php/praxiseducativa $>$ 
Piaget explora os limites e a caracterização dos jogos; a classificação dos jogos; as três grandes categorias de jogos; a evolução dos jogos e finda com a explicação dos jogos simbólicos.

A edição desse curso desvela outros focos das pesquisas de Piaget pouco relacionadas ao autor, que classicamente é indicado por seus estudos relacionados ao desenvolvimento do pensamento lógico-matemático. Entretanto, em relação à sequência dos estágios da evolução mental, que vão dos esquemas motores às representações pré-operatórias, das operações concretas às operações formais, Piaget expressou suas concepções sobre a afetividade. É pertinente a menção de que Piaget já havia inaugurado suas ponderações sobre as relações entre a afetividade e a inteligência na obra $A$ formação do símbolo na criança, publicada em 1945. De um modo geral, Piaget reconheceu na afetividade uma função essencial para constituição da inteligência, mas "não [como] uma condição suficiente" (PIAGET, 2014, p. 34) para explicar os comportamentos e a estrutura do pensamento cognitivo. Em suma, a forma com que foi organizado o presente curso, agora publicado no formato livro, denota que as concepções de Piaget são embasadas em problemas bem articulados que rompem com visões dicotômicas do homem. Afetividade e inteligência pressupõem relações de correspondência entre $o$ desenvolvimento de um e de outro, o que supera outras formulações teóricas pautadas em questões causais ou de complementaridade.

Para professores em atuação e para professores de licenciaturas que desejam permitir aos seus alunos a ampliação de suas percepções sobre as relações entre os aspectos cognitivos e afetivos, recomenda-se a obra, podendo ser inclusive fonte de incentivo e fomento para reflexões mais aprofundadas comparativamente a outras teorias educacionais.

\section{Referências}

DAMÁSIO, A. R. O erro de Descartes: emoção, razão e cérebro humano. São Paulo: Companhia das Letras, 1996.

LEITE, S. A. da S.; TASSONI, E. C. M. A afetividade em sala de aula: as condições de ensino e a mediação do professor. Campinas: Alle - textos, 2001.

PIAGET, Jean. Relações entre a afetividade e a inteligência no desenvolvimento mental da criança. Tradução e organização: Cláudio J. P. Saltini e Doralice B. Cavenaghi. Rio de Janeiro: Wak, 2014.

ULLER, W.; ROSSO, A. J. A interação da afetividade com a cognição no Ensino Médio. Schème - Revista Eletrônica de Psicologia e Epistemologia Genética, Marília, v. 2, n. 3, p. 195-219, jan./jul. 2009. 